IMECE2006-14420

\title{
TRAIN-TO-TRAIN IMPACT TEST OF CRASH ENERGY MANAGEMENT PASSENGER RAIL EQUIPMENT: OCCUPANT EXPERIMENTS
}

\author{
Kristine J. Severson \\ Daniel P. Parent \\ Volpe National Transportation Systems Center \\ U.S. Department of Transportation \\ Cambridge, MA 02142 USA
}

\begin{abstract}
As part of an ongoing passenger rail crashworthiness effort, a full-scale impact test of a train with crash energy management (CEM) passenger cars was conducted on March 23, 2006. In this test, a train made up of a CEM cab car, four CEM coach cars, and a locomotive impacted a stationary train of similar mass at $30.8 \mathrm{mph}$. This test included five occupant experiments on the cab car and the first coach car to evaluate occupant injury risk and seat/table performance during the collision using anthropomorphic devices (ATDs).

Three occupant protection strategies were evaluated in these occupant experiments. Forward-facing intercity seats were modified to reduce the high head injury risk observed in a previous test. Prototype commuter seats, included in both forward-facing and rear-facing orientations, were designed to mitigate the consequences of higher decelerations in the lead two CEM cars. Improved workstation tables, tested with two different advanced ATDs, were designed to compartmentalize the occupants and reduce the upper abdominal injury risk to the occupants.

Similar experiments were also conducted on the two-car impact test of CEM equipment [1]. The experiments described in this paper were conducted to evaluate the level of occupant protection provided by seats and tables that were specifically designed to improve crashworthiness. Pre-test analyses indicated that the occupant environment would be more severe for the CEM test than for the comparable test of conventional equipment. The environment in the leading cab car was predicted to be similar to a $12 \mathrm{~g}, 250$ millisecond triangular crash pulse. The environment in the first coach was predicted to be comparable to an 8g, 250 millisecond crash pulse.

To aid the design of the occupant experiments, occupant response models were developed for each of the occupant experiments using MADYMO. These models were developed for the previous two-car CEM full-scale test and adapted to the newly designed commuter seats and tables. Predictions of the occupant response during the CEM train-to-train test were developed before the test. The models were subsequently fine-
\end{abstract}

tuned to better agree with the test data, so that many different collision scenarios may be simulated.

Most of the test results were similar to the pre-test predictions. The modified intercity seats successfully compartmentalized the occupants. The risk of both head and neck injury, however, were above the respective injury threshold values. In the forward-facing commuter seat experiment the impacted seat experienced a partial failure of the seat pedestal attachment, resulting in loss of compartmentalization. The attachment failures occurred because the seats weren't fabricated as designed. However, the occupants were still compartmentalized, and the injury criteria were within survivable levels. The rear-facing commuter seat experiment experienced a more significant failure of the seat pedestal attachment, resulting in a loss of compartmentalization. The attachment failures likely occurred because the seats were not fabricated as designed and the collision was slightly more severe than predicted. To assure that this failure mode is prevented in the future, a more robust attachment is currently being developed. It will be tested quasistatically and dynamically to demonstrate its effectiveness. The improved workstation tables successfully compartmentalized the occupants while limiting the injury risk to acceptable levels.

\section{INTRODUCTION}

In support of the Equipment Safety Research Program of the Federal Railroad Administration (FRA), research is being conducted to develop strategies for improving structural crashworthiness and occupant protection in passenger rail vehicles. The structural crashworthiness research involves the modification of passenger rail equipment to preserve the occupant volume, which is necessary to prevent life-threatening injuries in rail collisions. This research has led to the development of the crash energy management (CEM) system, which consists of unoccupied crush zones at the ends of each car. Along with preserving the occupant volume, the CEM equipment includes features, such as deformable anti-climbers and pushback couplers, which inhibit override, lateral buckling, and other detrimental collision consequences [2]. 
Once the occupant volume is preserved, further strategies can be implemented to reduce injury risk. One proven strategy is compartmentalization or limiting the motion of the occupant to within the space between the launch seat and the impacted seat. If compartmentalization is lost, the occupant's trajectory is less predictable, and a risk of striking more hostile surfaces at a higher relative velocity exists. Additionally, the loads and accelerations imparted on the occupants by the seating arrangements that act in compartmentalizing the occupants must be within maximum injury criteria values. Typically, these maximum injury criteria values are at or below the acceptable injury threshold values prescribed by the National Highway Traffic Safety Administration (NHTSA) [3].

Three tools are commonly used to assist in this structural crashworthiness and occupant protection research: accident investigation, computer simulation, and testing. Accident investigation assists in determining the most likely collision or derailment scenarios, as well as the types and severities of injuries that occur. These scenarios influence the development of occupant protection strategies, as well as the implementation of tests. Computer simulations are used to evaluate the occupant injury risk and strategies to reduce the risk. Quasistatic load tests, dynamic sled tests, and full-scale impact tests are conducted to measure the crashworthiness performance of existing equipment and demonstrate the effectiveness of occupant protection strategies. The test data is used to fine tune and validate the computer models, which can then be used to evaluate a wider range of collision scenarios.

To measure the performance of existing equipment and demonstrate the effectiveness of CEM equipment, six full-scale in-line collision tests were carried out. Three tests were conducted for each set of equipment, gradually increasing in complexity. Single-car tests measured the mode of deformation and force-crush characteristic; two-car tests determined the interaction of coupled cars; and train-to-train tests determined the behavior of an entire passenger train. Table 1 lists the condition and date for each of the tests.

Table 1. In-Line Passenger Equipment Full-Scale Impact Tests

\begin{tabular}{|l|c|c|}
\hline \multicolumn{1}{|c|}{ Test Conditions } & $\begin{array}{c}\text { Conventional } \\
\text { Equipment }\end{array}$ & $\begin{array}{c}\text { Improved } \\
\text { Crashworthines } \\
\text { s Design } \\
\text { Equipment }\end{array}$ \\
\hline $\begin{array}{l}\text { Single-car impact with } \\
\text { fixed barrier }\end{array}$ & $\begin{array}{c}\text { Nov. 16, 1999 } \\
35 \mathrm{mph}\end{array}$ & $\begin{array}{c}\text { Dec. 15, 2003* } \\
34 \mathrm{mph}\end{array}$ \\
\hline Two-coupled-car impact & Apr. 4, 2000 & Feb. 26, 2004 \\
with fixed barrier & $26 \mathrm{mph}$ & $29 \mathrm{mph}$ \\
\hline Cab car-led train impact & Jan. 31, 2002 & Mar. 23, 2006 \\
with locomotive-led train & $30 \mathrm{mph}$ & $31 \mathrm{mph}$ \\
\hline
\end{tabular}

* No occupant experiments were conducted on the CEM test.

On five of the six impact tests (all but the CEM single-car test), occupant experiments were included inside the cars. These experiments use anthropomorphic test devices (ATDs, or test dummies) to measure the occupant response during the collision. A wide range of seating arrangements and orientations has been tested to date, including intercity seats with and without lap and shoulder belts (40-42 inch seat pitch), commuter seats (30-34 inch seat pitch) and facing seats with intervening workstation tables. The test data was analyzed to determine whether the occupants were compartmentalized and all injury measurements were within survivable levels.

The commuter seats and intercity seats tested previously on the conventional equipment needed relatively minor modifications to meet the existing requirements for occupant compartmentalization and injury criteria. However, the results from the two-car CEM test indicated that improved designs for intercity seats, workstation tables, and commuter seats were necessary to meet requirements in the leading cars of a CEM consist, which experience more severe accelerations than conventional equipment during a collision. Consequently, new workstation tables, commuter seats, and modified intercity seats were developed and tested during the CEM train-to-train test.

This paper will focus on the occupant experiments that were included on the CEM train-to-train impact test conducted on March 23, 2006. These experiments were conducted to evaluate the level of occupant protection provided by new seats and tables that were specifically designed to improve crashworthiness. Details about the structural aspects of the CEM train-to-train test can be found in a companion paper [4].

\section{DESCRIPTION OF OCCUPANT ENVIRONMENT}

Secondary impact refers to the impact between the occupant and some part of the interior, usually the forward seat, table, or bulkhead. Before a collision, the occupants travel at the same speed as the train. As the rail vehicle decelerates during the primary impact, unrestrained occupants gain velocity with respect to the car. The velocity of the occupant at the time of impact with an interior structure is referred to as the secondary impact velocity (SIV). The SIV generally increases with the distance traveled relative to the car for a range of typical seat pitches. At larger relative displacements, the SIV reaches a maximum value approximately equal to the closing speed of the train(s), assuming a plastic collision with a stationary train (the closing speed is the difference in velocity of the two colliding objects). The SIV, along with the stiffness and geometry of the interior structures impacted by the occupant, determine the severity of the secondary impact.

The crash pulse, i.e., the deceleration-time history of the rail car(s), and the configuration of the interior seats and tables are the key predictors of the severity of the occupant environment. The crash pulse determines the velocity at which the occupants impact the interior structures. One way to assess the severity of the crash pulse is to plot the relative velocity of an unrestrained occupant with respect to the car against the relative displacement of that occupant. This plot will indicate the velocity of the secondary impact over a range of occupant travel distances.

A pre-test collision dynamics model of the CEM train-totrain impact test [5] indicated that the modified force-crush behavior of the cars would result in a more severe crash pulse than in the train-to-train conventional impact test. In a train-totrain collision with conventional cars, the cab car environment 
will be less severe than a similar collision involving CEM equipment. The occupants of a conventional train will have a lower velocity at impact with an interior structure, as shown in Figure 1. However, a trade-off exists for the more benign secondary impact: in the conventional train-to-train impact test, the cab car sustained 22 feet of crush, compromising the survival space for 47 occupants plus the engineer [6, 7]. Additionally, the conventional equipment is likely to override, buckle laterally, and derail, all which introduce hazardous vertical and lateral accelerations to the occupant environment.

The crash pulse for the cab car in the CEM train-to-train impact test is more severe than the 8g, 250-millisecond triangular crash pulse that has been used in sled testing of rail seats [8]. To more accurately reflect the crash environment in a CEM cab car, a 12g, 250-millisecond triangular crash pulse was used to design the rear-facing commuter seats in the lead car. The crash pulse from the first coach car in the CEM trainto-train impact test is very similar to the $8 \mathrm{~g}$ pulse, which was used to design the forward-facing commuter seats located in the first coach car. Figure 2 plots the associated crash pulses.

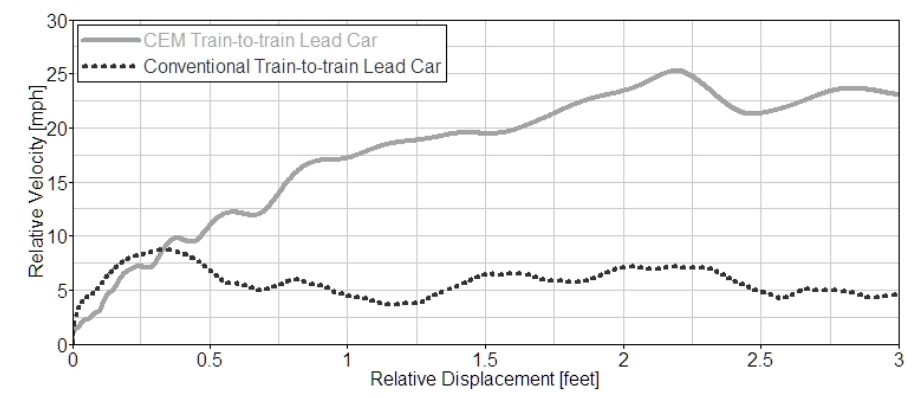

Figure 1. SIV Comparison

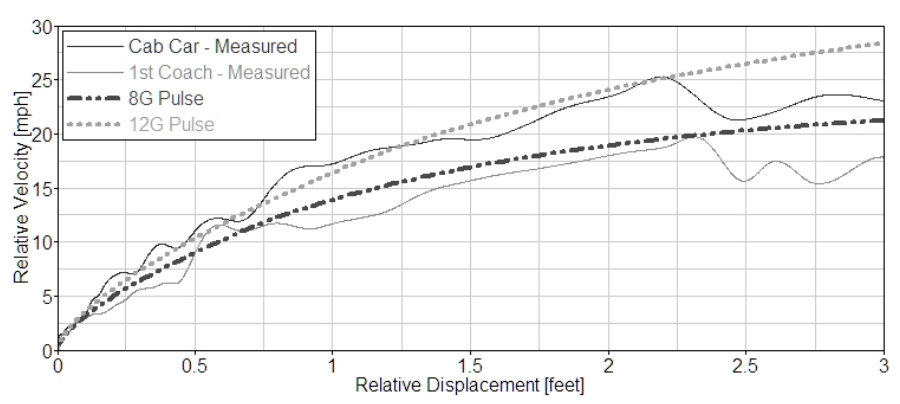

Figure 2. SIVs, Continued

The collision severity in the lead car of the CEM train-totrain impact test is very close to that in the lead car of the CEM two-car impact test. This minimizes the uncertainty when comparing the results from the baseline and improved workstation table experiments, as they were conducted in the lead car of their respective tests under similar conditions.

The output from the pre-test collision dynamics model was used as input for the MADYMO [9] occupant response models to assist in the design of the prototype commuter seats and improved workstation table. These occupant response models are used to estimate the likelihood of injury based on a specified crash pulse and the configuration of the interior structures. The models were developed for the previous CEM two-car impact test, refined to achieve better agreement with the test measurements, and then modified to include the improved seats and tables.

Similar to the tradeoff between preservation of occupant volume and SIV on the structural side, a tradeoff exists between occupant containment and harshness of the interior. Interior structures that deform significantly, while reducing the loads and accelerations imparted on the occupants, can also reduce the likelihood of compartmentalization. Occupant protection strategies are being developed to find the proper balance that will reduce the risk of secondary impact injuries.

On the CEM train-to-train impact test, three seating arrangements were evaluated: modified intercity seats, prototype commuter seats, and improved workstation tables. A total of five occupant experiments were conducted, as the commuter seats were included in both the forward-facing and rear-facing orientations, and two workstation table experiments were included using two different ATDs capable of measuring the upper abdomen-table interaction. Three of the occupant experiments were installed in the cab car, and the remaining two were in the first coach car. Figure 3 shows the layout of the occupant experiments conducted on the CEM train-to-train test.
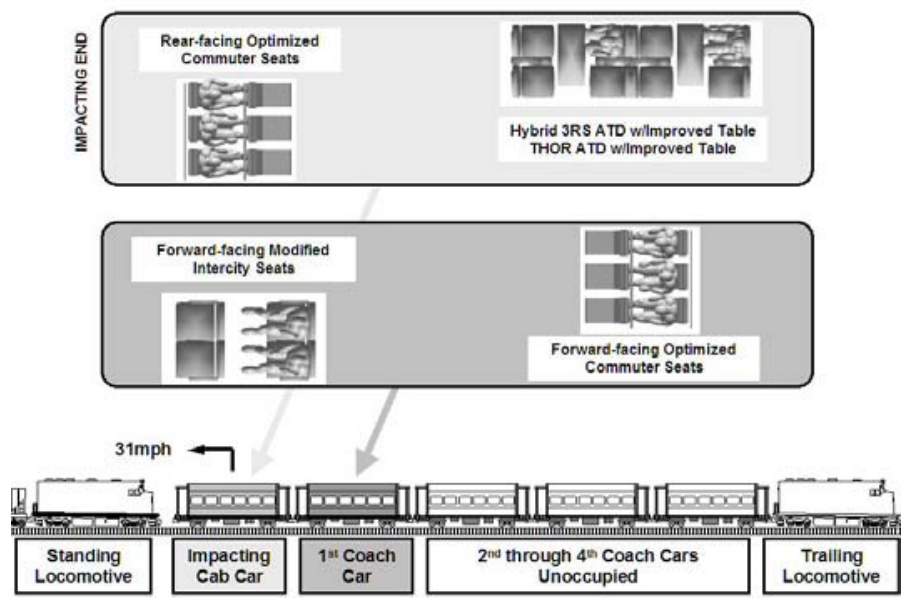

Figure 3. Location of Occupant Experiments

\section{OCCUPANT EXPERIMENT RESULTS}

\section{Intercity Seat Experiment}

The intercity seat experiment consisted of two pairs of forward-facing seats, with a seat pitch of 41 inches. These seats were modified in the same manner as the intercity seats in the two-car and train-to-train conventional tests, as well as the CEM two-car test, including strengthened seatbacks with an energy absorber in the base. These modifications were necessary to ensure compartmentalization of the occupant during a collision. During the CEM two-car impact test, the occupants were successfully compartmentalized. However, the impact of the head with the forward seatback exceeded the HIC15 injury criterion for both the aisle and window seat occupants. To reduce the severity of the head impact, a two- 
inch thick piece of padding was wrapped around the forward seatbacks. The objective of this experiment was to determine if this modification sufficiently reduces the head injury risk to the occupants.

Two Hybrid III 95 ${ }^{\text {th }}$ percentile male ATDs were positioned in the rear seat pair. Figure 4 shows a pre-test photo of the intercity experiment. The duct tape shown in these photographs holds the ATDs in their initial positions during the car's approach to the stationary train and is perforated so it does not affect their motion during the impact. The experiment was located near the front of the first coach car. The ATDs were unrestrained, as were all the ATDs in the CEM train-to-train impact test. Both ATDs were instrumented to measure the triaxial head and chest acceleration, axial femur load, shear and axial neck loads, and neck flexion/extension moment. A floormounted uni-axial accelerometer also measured the longitudinal car acceleration.

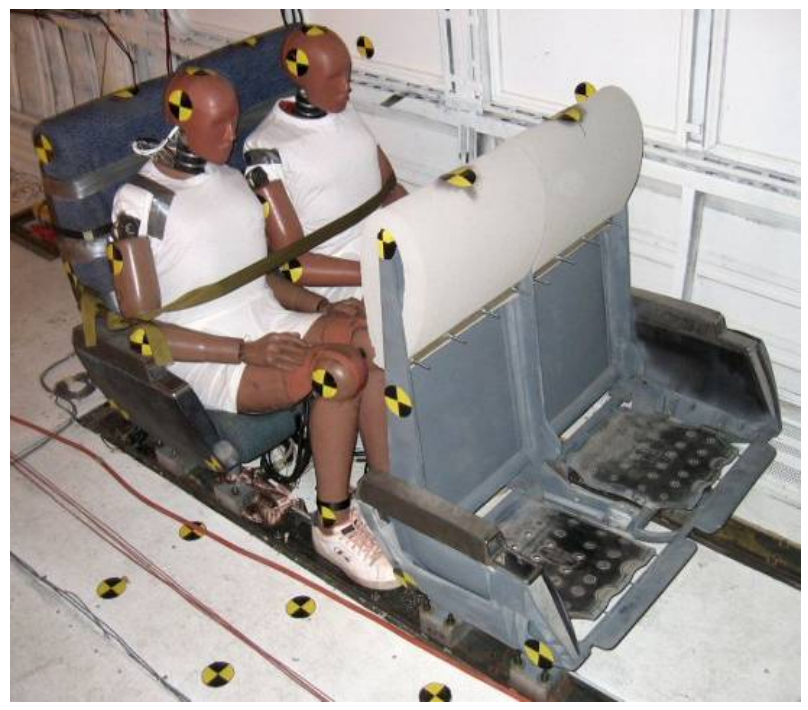

Figure 4. Pre-Test Photo of Intercity Seat Experiment

After the test, the high-speed video from both the side-view and top-view cameras was lost. Chalk was applied on the dummies before the test, however, so the locations on the seatback where the head, chest, and knees of each dummy impacted were known. Based on the post-test position of the dummies, it is clear that both occupants remained compartmentalized. The Head Injury Criterion (HIC) was exceeded for the aisle and window seat dummies. The Nij criterion was exceeded in compression/flexion for the aisle seat occupant. The chest acceleration criterion is relatively low in both dummies. The femur loads are well below the maximum criteria value. Table 2 shows the measured injury results.

Plastic deformation of the seat back panels occurred in both of the impacted seats. The panels caved inwards when impacted by the knees of the dummies, but they did not pull out the rivets at the bottom of the seatback as in the CEM two-car test. The seat pedestal itself did not deform. Figure 5 shows a post-test photograph.
Table 2. Preliminary Injury Results Intercity Seat Experiment

\begin{tabular}{|l|c|c|c|}
\hline Criteria & $\begin{array}{c}\text { Injury } \\
\text { Threshold } \\
{[10]}\end{array}$ & $\begin{array}{c}9^{\text {th }} \text { Percentile } \\
\text { Male, Window } \\
\text { Seat }\end{array}$ & $\begin{array}{c}95^{\text {th }} \text { Percentile } \\
\text { Male, Aisle } \\
\text { Seat }\end{array}$ \\
\hline HIC15 & 700 & 1476 & 1302 \\
\hline & & $0.05(\mathrm{Ntf})$ & $0.08(\mathrm{Ntf})$ \\
Nij & 1.0 & $0.41(\mathrm{Nte})$ & 0.33 (Nte) \\
& & $0.88(\mathrm{Ncf})$ & 1.04 (Ncf) \\
& & $0.33(\mathrm{Nce})$ & 0.27 (Nce) \\
\hline Peak Neck & $+1,131 /-$ & $+219 /-598$ & $+162 /-602$ \\
Fz, lbf & 1,089 & 16.61 & 13.32 \\
\hline Chest g & 55 & 823 & 909 \\
\hline Femur & 2,850 & 900 & 506 \\
Load, lbf & & &
\end{tabular}

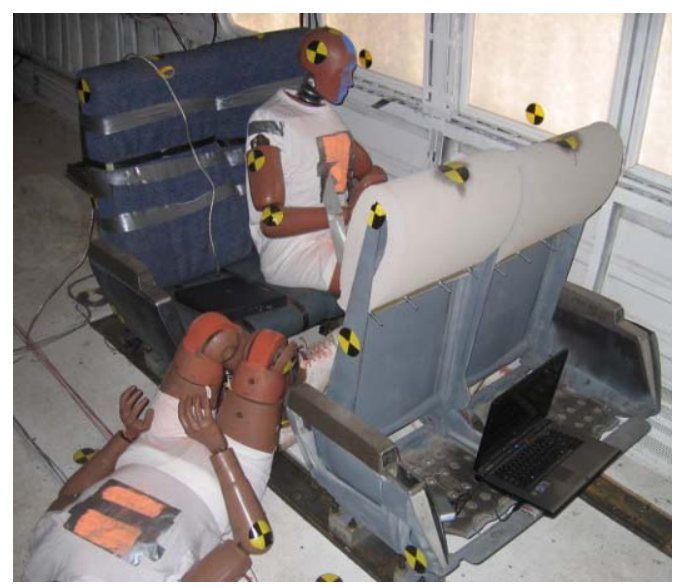

Figure 5. Post-Test Photo of Intercity Seat Experiment

The results from this experiment show that the modified seatback of the intercity seat is sufficient to compartmentalize the occupants. While the increased padding did reduce the head accelerations significantly for both occupants, the HIC15 values exceeded the acceptable levels. A post-test occupant response simulation suggests that the padding was not stiff enough, as the head penetrates the entire depth of the foam and impacts the rigid seatback behind it. Using padding that is twice as stiff would bring the head to rest before impacting the rigid seatback and keep the HIC15 criterion within survivable levels.

\section{Commuter Seat Experiments}

Two occupant experiments were conducted using threepassenger prototype commuter seats. These seats were developed specifically for use in CEM rail cars. Previous experiments using commuter seats in the conventional equipment tests indicated that the existing $\mathrm{M}$-Style commuter seat needed only minor modifications to meet the existing requirements for compartmentalization and injury criteria. The results from the two-car CEM test, however, indicated that an improved seat design was necessary to meet requirements in the leading cars of a CEM consist.

During development of the new seat, several requirements were established for occupant response and seat performance 
under dynamic test conditions [11]. To meet the occupant response requirements, the ATDs must be compartmentalized, and the injury criteria must be below the maximum limits defined in CFR 49 Part 571, Section 208: Occupant Crash Protection [3], which is used by the automotive industry. The American Public Transportation Association (APTA) Standard for Row-to-Row Seating in Commuter Rail Cars [8] must also be met, which includes seat performance requirements. The seat must remain attached to the test sled at all attachment points, and the permanent seat deformations must not significantly impede an occupant from standing and exiting the seat. Seat cushions must also remain fastened to the seat frame.

The new seat design is based on an existing two-passenger seat design that meets the APTA standard for row-to-row seating in commuter rail cars. The principle modifications to this design are a third passenger seat, a stronger seat back, and a taller headrest. When compared with the M-style seat, the prototype seat is stiffer, taller, and modular, with padding on the head impact surface and a knee bolster to transfer loads from the knees into the seat frame. Figure 6 shows a schematic of the prototype seat structure.

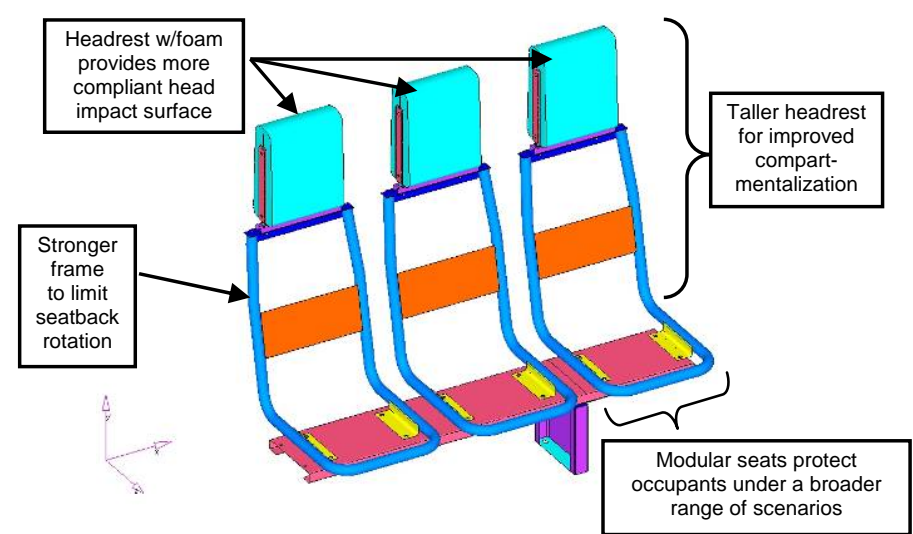

Figure 6. Schematic of Prototype Commuter Seat

In the rear-facing commuter seat experiment, two instrumented Hybrid III $50^{\text {th }}$ percentile male ATDs were located in the aisle and window positions of the rear seat. An uninstrumented Hybrid II $50^{\text {th }}$ percentile male ATD was located in the middle seat (see Figure 7). The seat pitch was 32 inches. The experiment was located near the front of the leading cab car. The ATDs in the window and aisle seat positions were instrumented to measure tri-axial head and chest acceleration, shear and axial neck loads, neck flexion/extension moment, and femur loads.

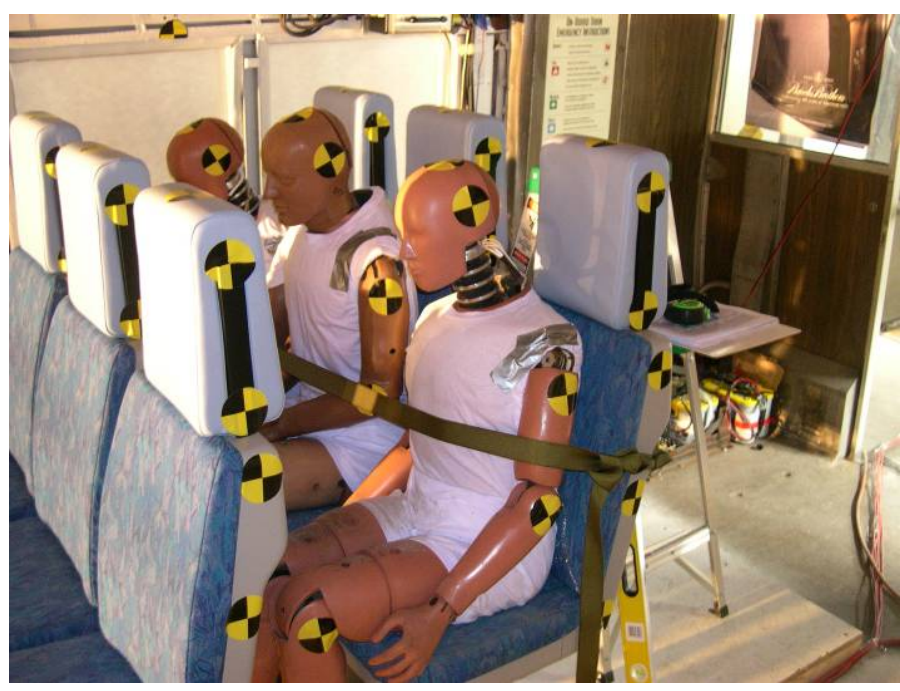

Figure 7. Pre-Test Photo of Rear-Facing Commuter Seat Experiment

After the test, the high-speed video from the side-view camera was lost. The top-view camera, post-test photos, and test data, however, provide a sufficient account of the test outcome (see Figure 8). The pedestal attachment failed near the beginning of the impact from the ATDs. Due to the large torque of the seat base, the aft bolts on the wall mount tore through the channel member, but the forward bolts on the wall mount kept the seat from detaching completely. The tethers on the ATDs prevented them from traveling further. Clearly the ATDs were not compartmentalized in this experiment, the seat did not remain attached at all attachment points, and the cushions of the aft seat separated from the seat frame. The injury criteria were all quite low, but this is irrelevant since the compartmentalization and seat attachment criteria were not met.

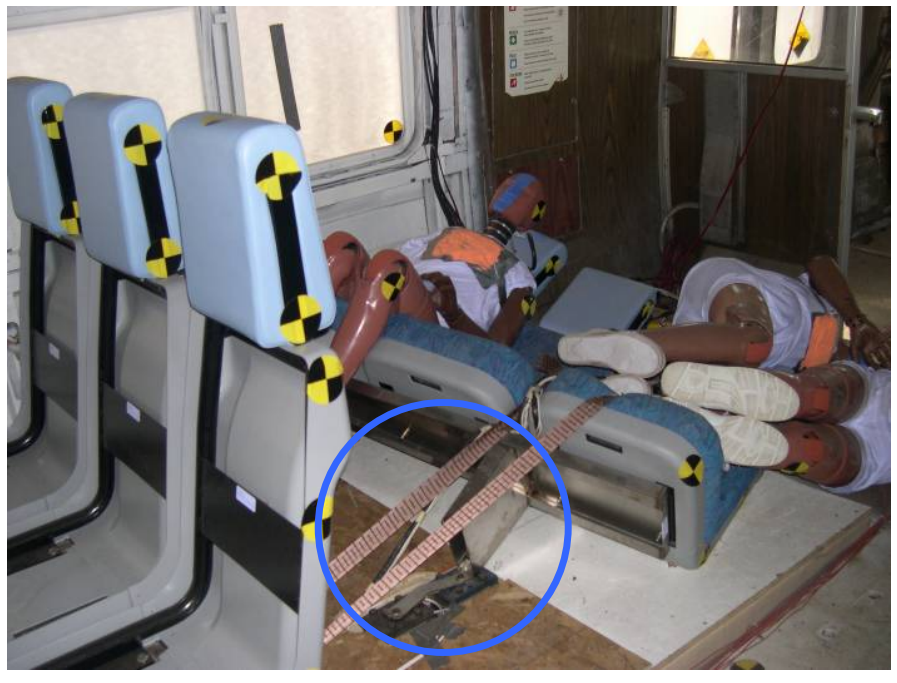

Figure 8. Post-Test Photo of Rear-Facing Commuter Seat Experiment

The floor pedestal was to have been continuously welded to a base plate, which was then bolted to the floor. Upon post-test inspection, it was discovered that the seats were not fabricated 
as designed. Instead, the pedestal was skip-welded to the base plate. Pre-test finite element analysis had indicated that a continuous weld would have been sufficient. Post-test finite element analysis indicated that the skip welding would create a critical stress area.

Ideally the seats would have been quasi-statically and dynamically sled tested before the full-scale test, but the seat design and test schedules prevented the appropriate order of tests. Plans are underway to fabricate a more robust pedestal attachment and quasi-statically test the seats to determine that the attachment is not on the critical load path. A modified seat retention mechanism will also be designed. After successful quasi-static tests, the seats will be dynamically sled tested using the 12g 250-millesecond triangular crash pulse to evaluate the seat performance and occupant response under loading conditions similar to those in the CEM cab car.

The forward-facing commuter seat experiment consisted of two forward-facing three-person prototype commuter seats. As in the rear-facing experiment, two instrumented Hybrid III $50^{\text {th }}$ percentile male ATDs were located in the aisle and window positions of the rear seat (see Figure 9). An uninstrumented Hybrid II $50^{\text {th }}$ percentile male ATD was located in the middle seat. The Hybrid III ATDs were instrumented to measure triaxial head and chest acceleration, axial femur load, shear and axial neck loads, and neck flexion/extension moment. A floormounted bi-axial accelerometer also measured the longitudinal and vertical acceleration.

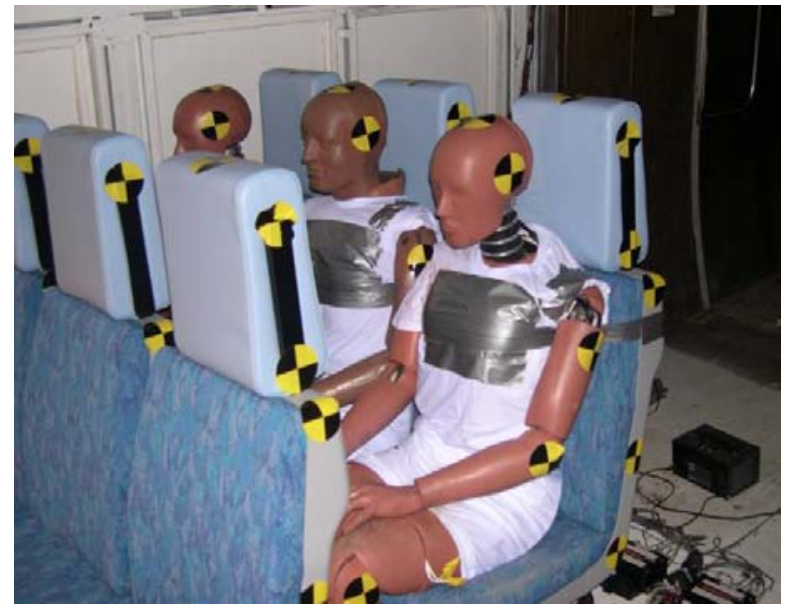

Figure 9. Pre-Test Photo of Forward-Facing Commuter Seat Experiment

Figure 10 shows a post-test photo of the forward-facing experiment. The results indicate that the ATDs were compartmentalized and that all the injury criteria were within nearly 50 percent of the maximum allowable values (Table 3). The APTA Standard states that, "An occupant is compartmentalized when the torso is confined within the perimeter defined by the front edge of the front row seat pan, the full width of the aisle, and the seat back surface of the launch seat." Even though two ATDs came to rest in the aisle beside the launch seat, they are still considered to have been compartmentalized.

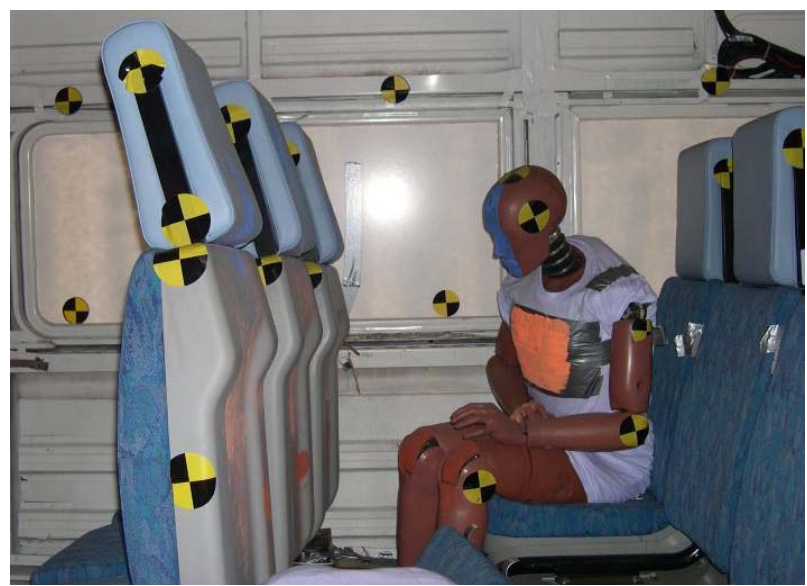

Figure 10. Post-Test Photo of Forward-Facing Commuter Seat Experiment

Table 3. Preliminary Injury Results for Forward-Facing Commuter Seat Experiment

\begin{tabular}{|c|c|c|c|}
\hline Criteria & $\begin{array}{c}\text { Injury } \\
\text { Threshold } \\
{[3]}\end{array}$ & $\begin{array}{c}50^{\text {th }} \text { Percentile } \\
\text { Male, Window } \\
\text { Seat }\end{array}$ & $\begin{array}{c}50^{\text {th }} \text { Percentile } \\
\text { Male, Aisle } \\
\text { Seat }\end{array}$ \\
\hline HIC15 & 700 & 378 & 221 \\
\hline $\mathrm{Nij}$ & 1.0 & $\begin{array}{l}0.04 \text { (Ntf) } \\
0.20 \text { (Nte) } \\
0.39 \text { (Ncf) } \\
0.04 \text { (Nce) }\end{array}$ & $\begin{array}{l}0.22 \text { (Ntf) } \\
0.33 \text { (Nte) } \\
0.25 \text { (Ncf) } \\
0.42 \text { (Nce) } \\
\end{array}$ \\
\hline $\begin{array}{l}\text { Peak Neck } \\
\text { Fz, lbf }\end{array}$ & +937/-899 & $+85 /-201$ & $+161 /-218$ \\
\hline Chest g & 60 & No data & 14.2 \\
\hline $\begin{array}{l}\text { Femur } \\
\text { Load, lbf }\end{array}$ & 2,250 & $\begin{array}{l}722 \\
442\end{array}$ & $\begin{array}{l}381 \\
677\end{array}$ \\
\hline
\end{tabular}

In this experiment, however, the skip welds at the base of the pedestal also experienced a partial failure, and two bottom seat cushions separated from the aft seat. The seat attachment loads were not great enough to cause a catastrophic failure as in the rear-facing case, but this deformation mode must be prevented. Figure 11 shows the occupant kinematics in the still photos taken from the high-speed film.

The occupant response measurements were fairly close to those predicted by the MADYMO model, even though the deformation mode was not as predicted. As shown in Figure 12, the predicted deformation mode was seatback deformation. The seat pedestal and base should remain fixed, while the tubular seat frame members deform plastically, absorbing energy in a controlled manner. The seat attachment, however, failed before sufficient force could be developed to deform the seat back, thus virtually no deformation of the seat back occurred. The entire seat assembly rotated nearly as a rigid body. While the deformation mode was not as predicted, the effective seat stiffness experienced by the ATDs was similar, thus resulting in similar injury criteria. 

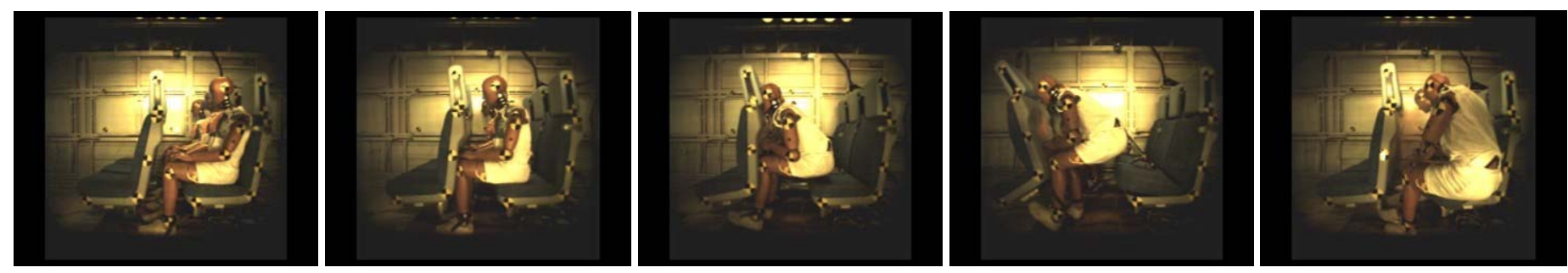

Figure 11. Time Sequence for Forward-Facing Commuter Seat Experiment

As in the rear-facing commuter seat experiment, the forward-facing experiment will also be dynamically sled tested after successful quasi-static tests of the modified pedestal attachment. The sled test will use an 8g, 250-millesecond triangular crash pulse, which simulates the collision environment in the first coach behind a leading cab car in a CEM consist. The seat performance and occupant response will be evaluated to demonstrate that the design requirements are met.

A. Predicted Deformation Mode Seatback Deformation

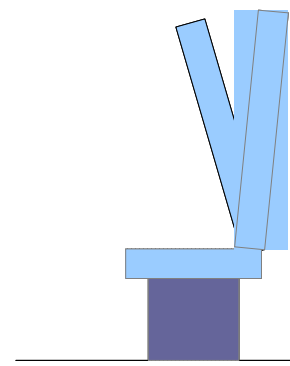

Figure 12. Schematic of Seat Deformation Modes

\section{Workstation Table Experiments}

Two occupant experiments were conducted using ATDs seated at improved workstation tables. The impetus for these experiments was a rail collision in which a MetroLink passenger train collided with a Burlington Northern Santa Fe Railroad freight train that occurred in Placentia, CA, on April 23, 2002. Two of the three fatalities were likely caused by abdominal/chest injuries due to impact with a workstation table [12]. Since this collision, work has been underway to design an improved table to reduce the risk of abdominal injury during workstation table impacts [13]. A baseline table design was included on the CEM two-car impact test. The results of this test confirmed a high risk of upper abdominal injury.

The improved table design tested in the CEM train-to-train test builds from a center support I-beam, which is cantilevered from the car wall and extends laterally from the wall completely to the aisle. The I-beam is designed to remain attached under the impact loads from two occupants during a collision, ensuring that the occupants remain compartmentalized. A small angled strut below the primary mounting points assists in supporting vertical service loads. The table edge is constructed of a crushable, energy-absorbing aluminum honeycomb. The honeycomb is oriented vertically with respect to the passenger car, which allows for the table edge to achieve the target force-crush characteristic while remaining stiff enough to meet the service load requirements. A layer of melamine is bonded to the aluminum honeycomb to form the tabletop. The bonding surface of the melamine is scored to promote separation from the honeycomb during an impact to prevent any contribution of the melamine to the force-crush characteristic of the table edge. A rounded rubber edge spans the perimeter of the table to assist in load distribution and present a benign impact surface to the occupants during a collision. Figure 13 shows a schematic of the improved workstation table.

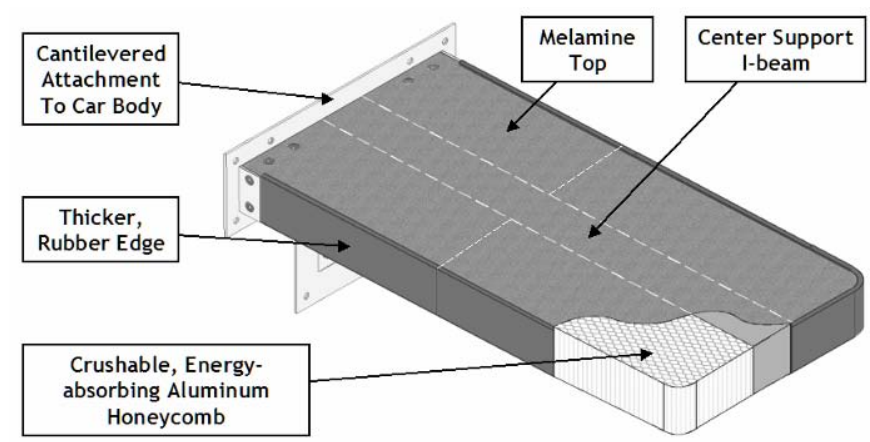

Figure 13. Improved Workstation Table

The objective of the table experiments was to demonstrate the performance of this improved table. A secondary objective was to evaluate the table against the crashworthiness design requirements. These requirements, determined during the development of the improved table, were designed to ensure that the upper abdominal injury risk to the occupant is reduced without introducing other injury risks. The primary crashworthiness requirement is that the occupant is compartmentalized. The requirement also specifies the maximum acceptable injury tolerance levels under an 8g, 250 millisecond longitudinal crash pulse, as shown in Table 4. These requirements are intentionally more stringent than the accepted NHTSA injury tolerance limits to ensure the crashworthiness of the table.

These numbers differ from the previously presented criteria [13] in two ways. First of all, the maximum abdominal force criterion has been removed. During initial analysis of the table design, it was determined that a table edge that crushes at a constant force just below the previously presented maximum tolerance level does not absorb sufficient energy to bring the occupant to rest before the table edge bottoms out. Additionally, there is not sufficient research detailing peak force levels for upper abdominal impacts using an impactor 
representative of the table edge. Much more applicable information is available on the correlation of upper abdominal compression and rate of compression to injury risk [14]. Thus, in exchange for the removal of the peak force criterion, the compression and rate of compression criteria for the chest and upper abdomen, as well as chest acceleration criterion, were tightened.

Before the full-scale impact test, the table was quasistatically tested. Three loading conditions were evaluated. The first two conditions examined the strength of the table under service loads. The table met the predetermined requirements in each case.

Table 4. Maximum Acceptable Injury Tolerance Levels for the Performance of an Improved Crashworthiness Performance Table Under an 8 G, 250 ms Crash Pulse

\begin{tabular}{|l|c|l|}
\hline \multicolumn{1}{|c|}{ Injury Criteria } & $\begin{array}{c}\text { Maximum } \\
\text { Tolerance }\end{array}$ & \multicolumn{1}{c|}{ Units } \\
\hline $\mathrm{HIC15}$ & 700 & \\
\hline $\mathrm{Nij}$ & 1.0 & \\
\hline Neck Tension & 4,170 & $\mathrm{~N}$ \\
\hline Chest Acceleration & 30 & $\mathrm{~g}$ \\
\hline Chest Compression & 60 & $\mathrm{~mm}$ \\
\hline Chest $\mathrm{V}^{*} \mathrm{C}$ & 0.8 & $\mathrm{~m} / \mathrm{s}$ \\
\hline $\begin{array}{l}\text { Upper Abdomen } \\
\text { Compression }\end{array}$ & 70 & $\mathrm{~mm}$ \\
\hline Upper Abdomen $\mathrm{V}^{*} \mathrm{C}$ & 1.25 & $\mathrm{~m} / \mathrm{s}$ \\
\hline
\end{tabular}

The final loading condition used two impactors that represent occupants to apply a longitudinal load to the table edge. The edges were crushed until the entire stroke of the aluminum honeycomb was exhausted. This test demonstrated that the table remains attached at and even above crush loads. It appeared, however, that the melamine on the top and bottom of the table was bonded too securely to the honeycomb. As a result, the melamine fractured and detached in an undesirable fashion, and the measured force-crush characteristic indicated both peak and average loads above the design requirement.

Since the quasi-static crush test was held before the fullscale CEM train-to-train impact test, an opportunity existed to modify the tables to improve the force-crush characteristic. Specifically, the method of bonding the melamine to the honeycomb was refined, and the grooves in the melamine were increased to half its depth.

Evaluating the injury risk to occupants at workstation tables requires test devices capable of measuring the abdomen-table interaction. In order to allow a more direct comparison between the baseline and improved tables, the same ATDs were used as in the CEM two-car test: the Test device for Human Occupant Restraint (THOR) [15] and the Hybrid 3RS [16]. In the test of the baseline table design, both ATDs measured upper abdominal compression and rate of compression above the acceptable injury tolerance levels. The THOR ATD measured chest acceleration above not only the design requirement but also the maximum acceptable tolerance level determined by NHTSA. Additionally, the head of the THOR impacted the tabletop, inducing head accelerations that approached the injury tolerance level. The improved table was designed to prevent all of these sources for injury.

The workstation table experiments on the CEM train-totrain test were designed to evaluate the crashworthiness performance of the improved table using the Hybrid 3RS (Figure 14) and the THOR (Figure 15), respectively. These two similar experiments each consisted of a facing-seat pair with an intervening workstation table. The pitch of the facing-seat arrangement is 65 inches, with the table centered between the two pairs of seats. The tabletop is 40 inches long by 20 inches wide by 3.5 inches thick. The top of the table is 32 inches from the floor.

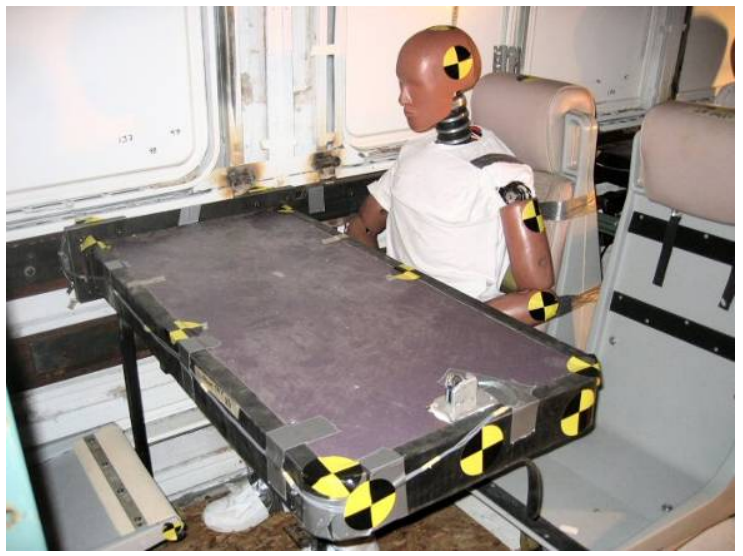

Figure 14. Pre-Test Photo of Table Experiment with H3RS ATD

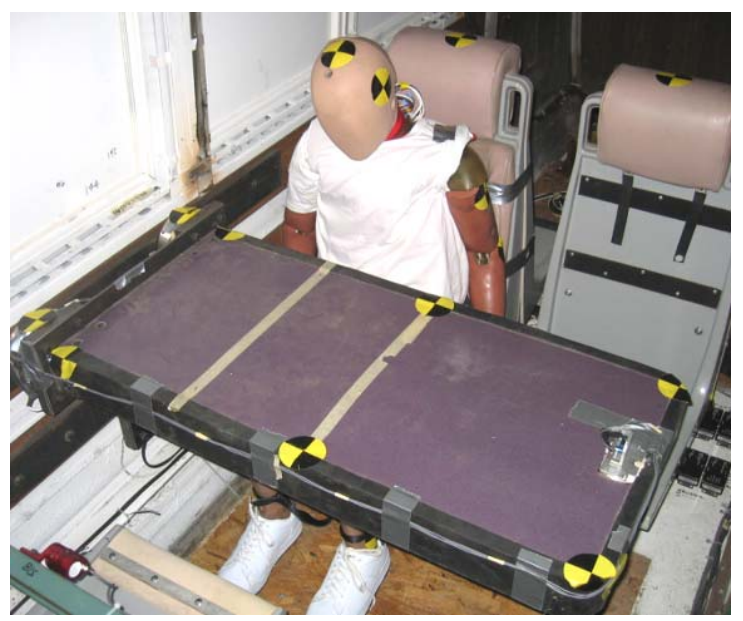

Figure 15. Pre-Test Photo of Table Experiment with THOR ATD

The Southern California Regional Rail Authority provided the facing seats for these experiments. Computer simulations implemented during the design of the improved workstation table indicated that the ability of the table to crush allowed more interaction of the lower legs of the occupant with the facing seat pan than in the baseline table case. Thus, a knee bolster was integrated into the facing seat pan by removing some of the rigid plastic material and replacing it with a layer of foam rubber.

Both ATDs were instrumented to measure tri-axial head and chest accelerations, axial femur loads, shear and axial neck 
loads, neck flexion/extension moment, and bi-lateral threedimensional displacements of the upper and lower rib cage. The THOR was also instrumented to measure linear displacement and acceleration of the upper abdomen. In addition, the table was instrumented to measure acceleration and longitudinal displacement of the aisle-side edge and crush of the edge to be impacted by the ATD.

A pre-test MADYMO [9] computer model was used to simulate the occupant response for each table experiment using the predicted crash pulse from the pre-test collision dynamics model [5]. All of the predicted measurements were below the maximum acceptable injury criteria values presented in Table 4.

The occupant response in the improved workstation table experiments was very similar to the pre-test predictions. Upon impact, the dummies translated towards the table in the longitudinal direction. Little or no displacement occurred in the vertical or lateral directions. The dummies' shoes initially began to slide along the floor and then dragged enough to cause rotation about the knee. The upper abdomen contacted the table just over 100 milliseconds after the initial train-to-train impact. First, deformation of the upper abdomen occurred, and then shortly thereafter the table edge began to crush. The table edge continued to crush until about 150 milliseconds, at which point the pelvis rotated forward, and the lower legs of the dummies impacted the knee bolster on the facing seat pan. At the same time, the upper body pitched forward slightly, and the neck flexed to allow the head to rotate toward the tabletop. Unlike in the baseline table case, however, the head did not contact the tabletop. The forward motion of the occupant was completely arrested after 175 milliseconds, at which point the occupant reversed direction and traveled toward the launch seat.

The biggest different in the kinematics between the Hybrid 3RS and the THOR occurred in the rebound from the table impact. As the Hybrid 3RS traveled backward toward its initial seat position, the rear of the pelvis contacted the seat pan and arrested the motion of the lower half of the dummy. This caused rotation about the pelvis, which led to an impact of the back of the head with the headrest. Fortunately, the headrest was sufficiently padded to prevent serious injury. The peak HIC and Nij shown in Table 5 were recorded at this point. The still frames in Figure 16, taken from the high-speed video, show the kinematics of the Hybrid 3RS.

As the THOR rebounded from the table, the pelvis did not catch on the seat pan, and the dummy returned to the initial seat position. Sufficient relative velocity existed between the occupant and the seat to cause extension of the neck and contact between the head and the headrest. This interaction, however, was unlikely to cause injury. The still frames in Figure 17, taken from the high-speed video, show the kinematics of the THOR.

All of the injury measurements evaluated in the table experiments were below the maximum injury criteria values. Table 5 shows the measured injury results. Table 6 compares an average of measurements from the two ATDs to the average measurements from the test of the baseline table design. The table also lists the design requirements for the improved table design. These design requirements are based on an occupant environment severity equivalent to an 8g, 250 millisecond triangular acceleration pulse. As mentioned earlier, the cab car environment resembles a more severe 12g, 250 millisecond triangular pulse. Since the improved table met the crashworthiness design requirements in a more severe occupant environment, it is assumed that these requirements would be met under the specified 8g pulse as well, thus no further testing is necessary.

Table 5. Preliminary Injury Results for Improved Workstation Table Experiments

\begin{tabular}{|l|c|c|c|}
\hline \multicolumn{1}{|c|}{ Criteria } & $\begin{array}{c}\text { Injury } \\
\text { Threshold }\end{array}$ & $\begin{array}{c}\text { Hybrid 3RS } \\
50^{\text {th }} \text { Percentile } \\
\text { Male }\end{array}$ & $\begin{array}{c}\text { THOR 50 } \\
\text { Percentile } \\
\text { male }\end{array}$ \\
\hline $\begin{array}{l}\text { Upper Abdomen } \\
\text { Compression } \\
\text { Ratio [17] }\end{array}$ & $50 \%$ & $29 \%$ & $26 \%$ \\
\hline $\begin{array}{l}\text { Upper Abdomen } \\
\text { V*C, m/s [18] }\end{array}$ & 1.98 & 0.96 & 1.13 \\
\hline Chest g & 60 & 21.2 & 28.7 \\
\hline HIC15 & 700 & 77.5 & 155 \\
\hline Nij & 1.0 & $0.29(\mathrm{Nte})$ & $0.33(\mathrm{Ntf})$ \\
\hline Neck Tension, lbf & $+937 /-899$ & $+270 /-202$ & $+360 /-90$ \\
\hline Femur Load, lbf & 2,250 & $226(\mathrm{~L})$ & $993(\mathrm{~L})$ \\
\hline
\end{tabular}

Table 6. Evaluation of Improved Workstation Table

\begin{tabular}{|l|c|c|c|}
\hline \multicolumn{1}{|c|}{ Criteria } & $\begin{array}{c}\text { Baseline } \\
\text { Table }\end{array}$ & $\begin{array}{c}\text { Improved } \\
\text { Table }\end{array}$ & $\begin{array}{c}\text { Improved } \\
\text { Table Design } \\
\text { Requirement }\end{array}$ \\
\hline $\begin{array}{l}\text { Upper Abdomen } \\
\text { Compression, } \\
\text { mm }\end{array}$ & 105 & 57.5 & 70 \\
\hline $\begin{array}{l}\text { Upper Abdomen } \\
\text { V*C, m/s }\end{array}$ & 1.38 & 1.05 & 1.25 \\
\hline Chest g & 60 & 25 & 30 \\
\hline HIC15 & 374 & 116 & 700 \\
\hline Nij & 0.58 & 0.31 & 1.0 \\
\hline Neck Tension, lbf & 798 & 315 & 937 \\
\hline Femur Load, lbf & 1,017 & 1,025 & 2,250 \\
\hline
\end{tabular}

In concurrence with the crashworthiness requirements for the improved table design, both tables remained attached and compartmentalized the occupants. The table edge performed as intended. The melamine top separated from the aluminum honeycomb and folded along the scored edges. This was possible due to the modifications made after the quasi-static test and allowed the desired force-crush characteristic to be achieved. The aluminum honeycomb crushed between 5 and 6 inches, indicating a peak force of roughly 2,000 pounds. This is a significant reduction from the peak load measured in the baseline table case. The table impacted by the Hybrid 3RS crushed more than the table impacted by the THOR; this was no surprise, as the Hybrid 3RS has a stiffer upper abdomen than the THOR [16]. Figure 18 and Figure 19 are post-test photographs of the table experiments, showing the final position of the ATDs and the crush of the aluminum honeycomb. 


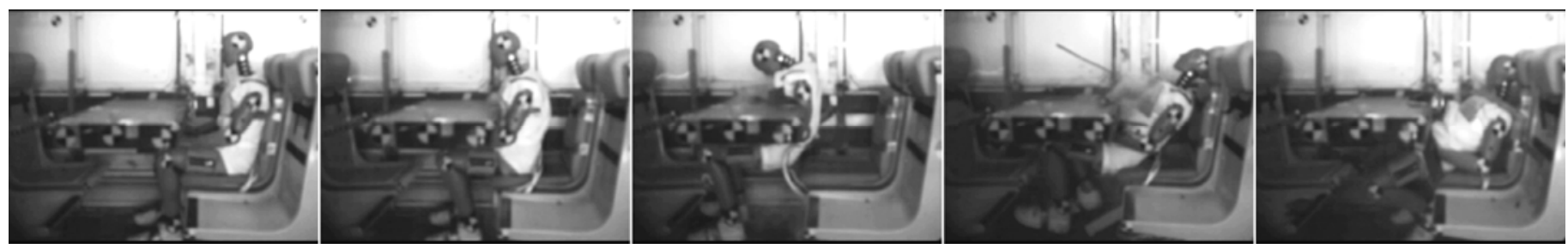

Figure 16. Time Sequence for Workstation Table Experiment with H3RS ATD
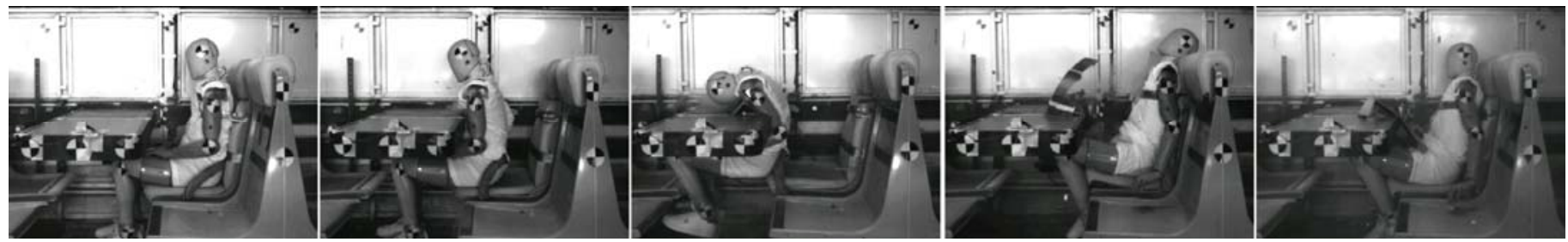

Figure 17. Time Sequence for Workstation Table Experiment with THOR ATD

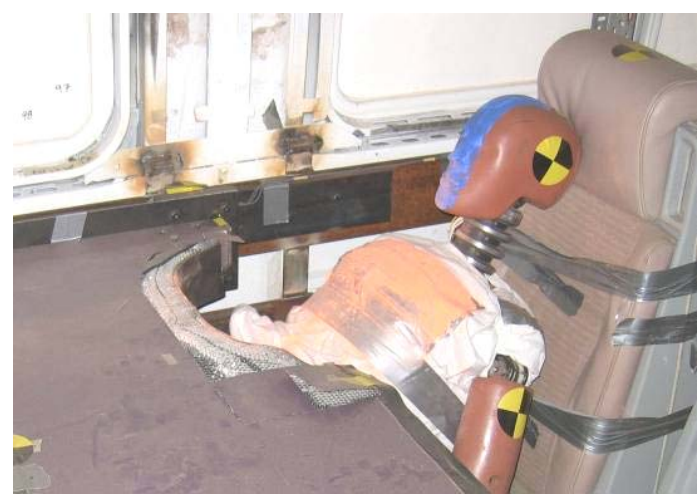

Figure 18. Post-Test Photo of Table Experiment with H3RS ATD

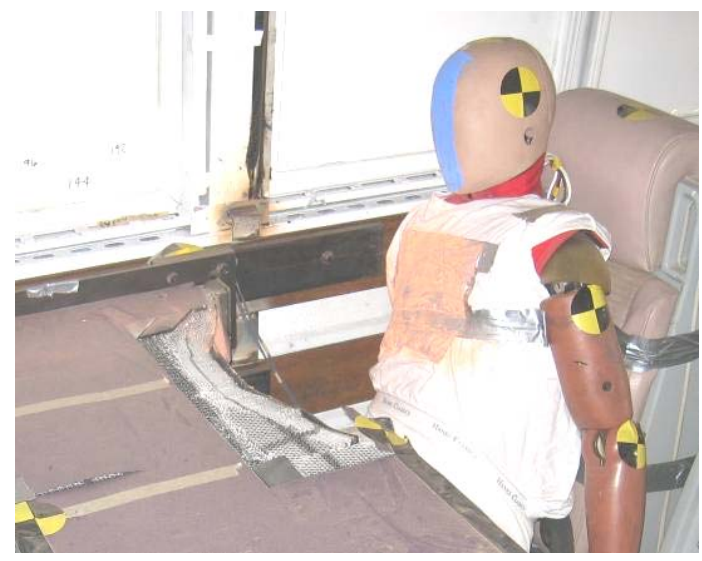

Figure 19. Post-Test Photo of Table Experiment with THOR ATD

While the improved table successfully protected both ATDs, there is more work to be done. The table needs further refinement before it can be used in service. Weighing in at roughly 80 pounds, it is likely too heavy for installation on current passenger rail vehicles. Furthermore, the required attachment strength could necessitate stiffening of the car body in the area where the table would attach to the wall. It is possible that the support structure could be optimized, such as removing material from the low-stress areas of the center support I-beam, to reduce this weight. Initial reaction from the rail industry indicates that a table with a pedestal leg is desirable to bear the vertical service loads, as well as reducing vibration response.

Improvements can also be made to the table's crashworthiness performance. One similarity between the baseline table and the improved table is that the rate of abdominal compression over the first 10 milliseconds of table contact is nearly identical. This occurs because, up to a certain point, the table is stiffer than the upper abdomen, so the upper abdomen will deform. Once the force necessary to compress the upper abdomen reaches the force to initiate crushing of the table, the rate of upper abdominal compression slows. While this does not appear in the injury measurements, it could still lead to soft tissue injuries. A solution to this problem would be to integrate a rubber edge of stiffness similar to that of the abdomen. This will decrease the rate of upper abdominal compression before the table edge begins to crush.

The fit and finish of the table could use refinement as well. The rubber around the edge became loose during the installation of the table on the test car. A production design would feature an extruded rubber edge with a marine edge to improve the maintainability of the table. In addition, some pieces of the melamine top detached during the impact, presenting sharp fragments that could be hazardous to the occupants. The melamine would be replaced with a more ductile material in a production design.

Finally, the improved table should be evaluated in a wider range of collision scenarios, including different crash pulses and different occupant sizes. This can be done analytically, since the computer simulations conducted before the test were accurate in predicting the results of these experiments. Further model refinements made after the test to account for initial positions of the test dummies and fine-tune contact 
characteristics allow close agreement between the test data and the simulation results. This inspires confidence that the model can be used to simulate a wider range of collision scenarios.

\section{SUMMARY AND CONCLUSIONS}

Five interior occupant experiments were conducted as part of the train-to-train impact test of CEM equipment. Each of these experiments was similar to those conducted in the previous two-car CEM impact test. The objective of these tests was to evaluate the performance of improved seats and tables, as well as to measure the occupant response under collision conditions of CEM equipment.

As described previously in this paper, the decelerations experienced by the cars during the CEM train-to-train test were quite severe. In spite of the severe collision environment, several improvements to occupant safety were quantified.

The HICs measured in the intercity seat experiment were reduced significantly from the two-car CEM test; however, they are still not below the maximum allowable threshold. Stiffer and/or thicker padding on the seat back has been identified as a means to further improve the head and neck injury measurements.

The prototype commuter seat experiments suffered failure at the seat pedestal attachment to the floor. The seat attachment failure in the rear-facing seat experiment was so severe that occupant compartmentalization was lost. The seat attachment failure in the forward-facing experiment was less severe and allowed the compartmentalization of the occupants, while also limiting all injury criteria measured to roughly half of the maximum allowable levels. The seat attachment method is being analyzed, and an improved attachment method will be tested under quasi-static and dynamic sled test conditions to demonstrate that the design requirements are met.

The workstation table experiments demonstrated that the design requirements were met and that the table performed as expected. The table remained fastened to the wall, and the injury criteria were all within the specified maximum thresholds.

The overall test demonstrated that the CEM design successfully preserved all the occupant volume for the locomotive engineer, as well as the passengers. The occupant experiment results indicate that, even though the secondary impact environment in the CEM train-to-train test was more severe than that of the conventional train-to-train test, steps can be taken to mitigate the higher SIVs.

\section{ACKNOWLEDGMENTS}

The research described in this paper was performed as part of the Equipment Safety Research Program sponsored by the FRA's Office of Research and Development. The authors would like to thank Claire Orth, Chief, Equipment and Operating Practices Division, for her support. Dr. Tom Tsai, Program Manager, led this effort. Gunars Spons, FRA Resident Manager at the Transportation Technology Center, managed the full-scale test effort. Grady Cothen, Deputy Associate Administrator for Safety Standards and Program Development, has coordinated FRA's regulations development and the passenger rail equipment crashworthiness research since the inception of this research. The authors would also like to thank Volpe Center colleagues David Tyrell, Senior Engineer, and Eloy Martinez, Senior Engineer, for their efforts in designing the impact test, including overseeing the fabrication of the crush zones and integration of the crush zones into test cars; Karina Jacobsen, Mechanical Engineer, for development of the collision dynamics model used to predict the occupant environment before the test; A. Benjamin Perlman, Professor at Tufts University, for technical guidance and assistance in editing this paper; Michelle Priante, Mechanical Engineer, and Michael Carolan, Mechanical Engineer, for their assistance in oversight of the test implementation and documentation of the test results.

Matthew Witte, Senior Engineer, led the TTCI team that implemented the test. Tom Roderick, Senior Technician, assisted in preparing the interiors of the test cars. Bob Rancatore of TIAX, LLC, and his team provided oversight in the implementation of the occupant experiments, design and fabrication of the prototype commuter seats, and design, fabrication, and testing of the improved workstation tables. Chris Bradney of Simula, Inc. and his team installed the seating arrangements, interior instrumentation, and test dummies. Caroline VanIngen-Dunn, CVID Consulting, assisted on-site in the implementation of the occupant experiments. Jay Gordon and Chuck Monson, GMH Engineering, installed the data acquisition system and assisted in preparing the test dummies. Kris Balch, Motion Video Products, installed the high-speed digital video cameras to record the interior experiments. Dr. Tariq Shams, GESAC, Inc., provided on-site expertise in preparing the THOR dummy.

The authors are grateful for the assistance provided by Peter Martin, THOR Program Manager at the NHTSA National Transportation Biomechanics Research Center, for arranging for use of a THOR dummy; GESAC, Inc. for preparing the THOR in time for the test; Peter Matthews and the United Kingdom's Rail Safety and Standards Board for providing the Hybrid 3RS dummy; and Joe McFadden of NHTSA's Vehicle Research and Test Center for providing the Hybrid III dummies.

\section{REFERENCES}

[1] Severson, K., Parent, D., Tyrell, D., “Two-Car Impact Test of Crash Energy Management Passenger Rail Cars: Analysis of Occupant Protection Measurements," American Society of Mechanical Engineers, Paper No. IMECE2004-61249, November 2004.

[2] Martinez, E., Tyrell, D., Rancatore, R., Stringfellow, R., Amar, G., "A Crush Zone Design for An Existing Passenger Rail Cab Car," American Society of Mechanical Engineers, Paper No. IMECE2005-82769, November 2005.

[3] Code of Federal Regulations, Title 49, Part 571, Standard 208 Occupant Crash Protection, October 2002.

[4] Tyrell, D., Jacobsen, K., Martinez, E., Perlman, A.B., "Train-to-Train Impact Test of Crash-Energy Management Passenger Rail Equipment: Structural Results,” American Society of Mechanical Engineers, Paper No. IMECE200613597, November 2006. 
[5] Tyrell, D., Jacobsen, K., Parent., D., Perlman, A.B., "Preparations for a Train-to-Train Impact Test of Crash-Energy Management Passenger Rail Equipment,” American Society of Mechanical Engineers, Paper No. IMECE2005-70045, March 2005.

[6] Tyrell, D., "Passenger Rail Train-to-Train Impact Test Volume I: Overview and Selected Results,” U.S. Department of Transportation, DOT/FRA/ORD-03/17.I, July 2003.

[7] VanIngen-Dunn, C. "Passenger Rail Train-to-Train Impact Test Volume II: Summary of Occupant Protection Program,” U.S. Department of Transportation, DOT/FRA/ORD-03/17.II, July 2003.

[8] APTA SS-C\&S-016-99, Rev. 1, Standard for Row-to-Row Seating in Commuter Rail Cars, The American Public Transportation Association, Washington, DC.

[9] MADYMO 3D, Release 6.1, TNO Road-Vehicles Research Institute, Delft, The Netherlands.

[10]Eppinger, R., Sun, E., Kuppa, S., and Saul, R., "Development of Improved Injury Criteria for the Assessment of Advanced Automotive Restraint Systems-II," Supplement to NHTSA Docket No. 1998-4405-9, 2000.

[11] Severson, K., Tyrell, D., Rancatore, R., "Crashworthiness Requirements for Commuter Rail Passenger Seats,” American Society of Mechanical Engineers, Paper No. IMECE200582643, November 2005.

[12] National Transportation Safety Board, "Collision of Burlington Northern Santa Fe Freight Train with Metrolink Passenger Train, Placentia, California, April 23, 2002," Railroad Accident Report NTSB/RAR-03-04, adopted on October 7, 2003.

[13] Parent, D., Tyrell, D., Rancatore, R., Perlman, A.B., "Design of a Workstation Table with Improved Crashworthiness Performance," American Society of Mechanical Engineers, Paper No. IMECE2005-82779, November 2005.

[14] Viano, D.C., and Lau, I.V., “A Viscous Tolerance Criterion for Soft Tissue Injury Assessment,” Journal of Biomechanics, Vol. 21, p. 387, 1988.

[15]Haffner, M., et al., "Foundations and Elements of the NHTSA THOR Alpha ATD Design,” paper 458, presented at the $17^{\text {th }}$ International Technical Conference on the Enhanced Safety of Vehicles, Amsterdam, Holland.

[16] Parent, D., Tyrell, D., Perlman, A.B., "Evaluating Abdominal Injury in Workstation Table Impacts,” Compendium of Papers, 84th Annual Meeting, Transportation Research Board, January 2005.

[17] Rouhana, S.W., Viano, D.C., Jedrzejczak, E.A., and McCleary, J.D., “Assessing Submarining and Abdominal Injury Risk in the Hybrid III Family of Dummies," Proc. $33^{\text {rd }}$ Stapp Car Crash Conference, pp. 257-279, SAE Technical Paper No. 892440, October 1989.

[18] Wallace, W.A. and Srinivasan, S.C.M., "Rail Passenger \& Crew Survivability Studies-Part 2,” November 2002. 